\title{
Block Chain Technology Progress and Challenges in Capital Markets
}

\author{
U.Padmavathi
}

\begin{abstract}
The blockchain is anunseen technology that is completelychanging the future of the world economy and achieving grip in the capital markets. Blockchain technology will have huge impact in business transaction and exchange of digital currency between financial institution. The technology is applied to a wide variety of financial fields, including business services, settlement of financial assets, prediction markets and economic businesses. While research has focused on identifying the reasons, Is in Capital Market the implementation of blockchain technology is how far it is acceptable and adapted for the present process with the capital market infrastructure.An effort is made in this paper to know the application and key challenges and implementation of blockchange technology in capital market.
\end{abstract}

Keywords: Blockchain technology, Capital market, Investment, Ledger System.

\section{INTRODUCTION}

The blockchain technology making a dynamic change in upcoming future of the world economy and gaining in the capital markets. Big companies are competing to build blockchain platforms. The technology will interrupt the upcoming of digital conversion across industries and big business. The blockchain is a digitized, disseminated, decentralized, and incorruptible public ledger of all digital assets and economic transactions that are noted in sequential order within a worldwide network called peer-to-peer $(\mathrm{P} 2 \mathrm{P})$ of spread 'nodes' or computers.

A few years ago Satoshi Nakamoto, the unidentified person/group behind Bitcoin, defined how the blockchain technology, a distributed peer-to-peer interrelated -structure, could be used to resolve the difficult of keeping the order to transactions and to evade the double-spending problem.

The major benefits of a blockchain are confirmation, clearness, and auditing which eradicates the actuality of the intermediaries. Major financial institutions and tech giants are booming out blockchain technology focused innovations. Such technology has been adopted by most of the industries, including the banking sector and financial institutions. So, blockchain has the capacity to allow multiple contracts to transfer and store important data in an environment that is secret, safe, permanent, and simplyavailable. Such technology convert the tough data into the simplify the expensive, paper-heavy and logistically complex financial processes such as cross-border transfer, payments, shareholder management, securities exchange, and ownership exchange.

As stock markets increasing globallytaking on blockchain's native skills as the basis for market transactions, the Securities and Exchange Board of India

Revised Manuscript Received on September 10, 2019.

U.Padmavathi*, Business Administration Department, Osmania University, Newtons Institute of Engineering, Hyderabad, Telangana, India.
(SEBI) is discovering how blockchain technology can be used in the Indian Stock market. Recently, SEBI appointed an advisory committee, called Committee on Financial and Regulatory Technologies (CFRT), for conducting research on the blockchain platform and other technologies that have been making influences in the scope of fundraising, asset management and post-trade settlement.

Blockchain can be the reply to interoperability, expectation and clearness issues in fragmented market systems. All the participants in the Stock market such as traders, brokers, regulators and stock exchange are required to go through a bulky process it takes nearly three days plus to finish the transactions because of mainly due role of intermediaries, personal trade clearance and regulatory processes.

Blockchain can be easy process by using maximum automation and decentralization process. It help a lot to reduce the high costs on customers in terms of commission and for speeding up the process for fast transaction settlements.It also helps in eliminating the use of the third party operator to a big extent, all the rules and regulations would be in-built under smart contracts and enforced with each business in order to register transactions with blockchain network performing as a regulator for all transactions.

\section{REVIEW OF LITERATURE}

(Nakamoto, 2008) Related to blockchain the first article was published in the year 2008 by a author Satoshi Nakamoto and the title of the article is Bitcoin. But so far the person or group name has not revealed. It describe that the blockchain technology is a peer-to-peer system and it is online payment is done from one party to another party through financial institution.

(Brito and Castillo, 2013) In the year 2009, A program is done, it is called Bitcoin, Since from the year 2009 onward the transaction took place. The first transaction begin from and took a importance took high in the year 2010 and also in the year 2011 too. Started using the first digital currency, it started reducing the problems and solving without any requirement of intermediators. 
Haferkorn and Quintana Diaz, (2015), Van de Velde et al., 2016; Wu and Liang 2017In recent days the blockchain technology is applying to all the maximum fields such as financial institutions, service sector, purchasing, in capital market, derivatives market for transaction or exchange of currency by using the digital currency, etc.

(Tapscott and Tapscott, 2016)Almost the valued of the Bitcoin has increase in the market and it's value increased to \$ one billion in the month of May 2013 and which is equal to one thousand percentage.

Most of the public focus on cryptocurrency. Day by day the Block chain Technology Progress and Challenges In Capital Markets. value of the blockchain technology and Bitcoin awareness is increasing. In upcoming years the value of will increase.

\section{OBJECTIVES OF THE STUDY}

1. To study the importance and relevance of blockchain technology towards capital market.

2. To study exploring way of using blockchain technology application for capital market.

3. To study the key challenges involved in capital market by using blockchain technology.

\section{A. Scope Of The Study}

The current study has been considered the building blocks and transaction takes place in blockchain technology and also the application of technology and challenges in capital market.

\section{B. Research Methodology}

The current study has been considered only secondary data. Source like:

- Journals

- Magazines

- Business line News Paper,

- Websites etc.

\section{Importance And Relevance}

Few years back centralized network, used to maintain all the transactions are checked by the central authority. The each ledger is verified in a ledger system. Each participant in network have they own record of ledger transaction and all the data is added to the blockchain database. In a capital market transaction, by using the blockchain technology no need of any intermediaries and completely ledger system is peer-to-peer basis.

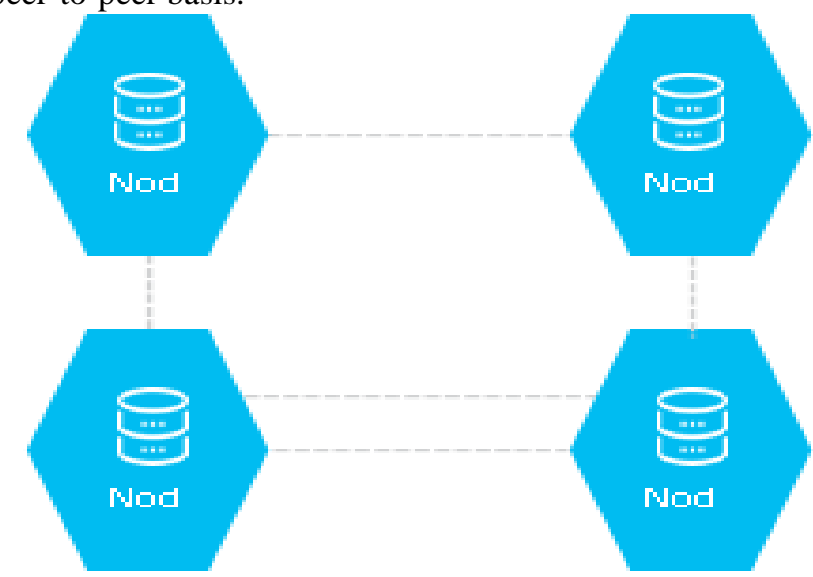

De-centralized Ledger Network

\section{Building Blocks Of Blockchain}

The most purpose of blockchain technology is to distribute the ledger with peer-to-peer design, it contains the decentralized method and digital sign.

\section{E. Distributed Ledger}

A member who is using the blockchain technology, It will store all the data of individual participant in a distributed network, without any involvement by an central authority. All the data stored in each separate ledger in blocks, each block has reference to the preceding block.

\section{F. Blockchain}

The blockchain data structure contain all the list of blocks transactions. After finishing of decentralized consensus process it will add to its existing chain and it also maintain a link with the previous block to genesis block.

\section{G. Nodes}

Nodes are the members who do the transaction in blockchain network. Members can be Full nodes and Partial nodes. The difference is full nodes can store the complete blockchain ledger locally whereas partial restricted to a limit.

\section{H. Permissioned/Private}

The participant those have permission such member can only have a access to use the blockchain network. Only selected participants can manage all the private network by using KYB or KYC procedure. Such private blockchain technology is used by financial institution.

\section{Validation/Consensus Mechanism}

Whenever a new transaction is received through message to the blockchain network. It is added to unchecked and transactions. But each node should legalize to standard one.

\section{J. Cryptography}

All the transaction which is done by using the blockchain network is cryptographically encrypted, All details related to the participants put under the confidential and each one will be provided with a private key and corresponding public key. By it there can operate the transactions. 


\section{MATH BLOCKCHAIN TECHNOLOGY APPLICATION IN TRASACTION}

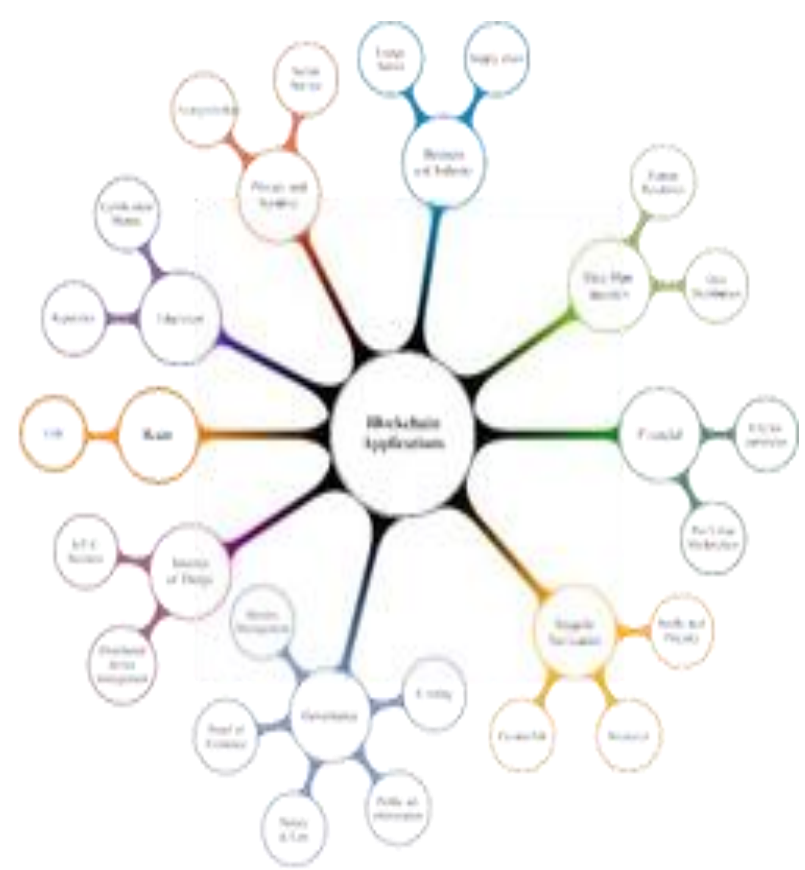

Mindmap abstraction of the different types of blockchain applications.

\section{KEY CHALLENGES RESULTS}

\section{A. Non Reversibility}

If any transaction once recorded blockchain, it cannot be directly changed or modified, if it want to make changes in the transaction it has to pass a new transaction but the old information will be remained same and it is stored as historical data. It becoming a big problem for trade validation.

\section{B. $\quad$ Trade Matching And Omission Management}

At present the technology does not have the same functionality in other place. So, a question raises that it is possible to handle the technology properly.

\section{Netting Of Positions}

Till now if any transaction has to done, it only depend on direct transaction of, Bitcoin is done by using the blockchain technology and all the payment has done only on payment basis. It require huge liquidity to make payments.

\section{Cash Leg Of A Transaction}

Even though the blockchain technology have complete security in transaction process and settle almost. Still the digital currency does not have any support formthe central banks globally. Almost the blockchain technology contain a security but the key challenge is maximum of them will accept the cryptocurrency are not in present market.

\section{E. Operational Challenges}

It is becoming tough to maintain blockchain multiple transaction in cases of sensitive and privacy point of view. Operational risks is going to increase because information might ge compromised as multiple copies of transaction kept across all the nodes in the network.

\section{F. Regulatory Impact}

New guidelines are expected where blockchain technologies become an essential part of the market infrastructure. A large number of laws required to be reinterpreted to deal with the new way of processing trades.

\section{CONCLUSION}

The effectiveness of the blockchain technology is huge, but the major question is how a participate make use and try to adapt and realize the benefits of technology in the future. Maintaining the peer-to-peer exchange process without any centralized observing authority and accorddevice to authenticate and maintain the same ledger copy among all the network participant are some of the important factors that can have a more impact in the process toward capital market. The blockchain technology is in growing stage, and the problem of security and safety is still in minds of many financial institutions and capital market participants.But it is attracting the most of the interest, but the technology should not motivate one to navigate this unchartered area without being alert.

\section{REFERENCES}

1. http://www.the-blockchain.com

2. www.dtcc.com

3. www.mckinsey.com

4. https://www.blockchain-council.org

5. https://bitcoin.stackexchange.com

6. http://santanderinnoventures.com

7. https://www.blockchaindailynews.com

8. https://www.coindesk.com

9. https://www.economictimes.com. 